\title{
BIOÉTICA DE LA VIDA Y DE LA MUERTE EN SÉNECA, RAZONES SOCIOPOLÍTICAS PARA MORIR
}

\section{BIOETHICS OF LIVE AND DEATH IN SENECA'S THOUGHT, SOCIOPOLTICAL REASONS FOR DAYING}

\author{
Dra. Karla Vargas Vargas \\ Universidad de Costa Rica, Costa Rica \\ karla.vargas@ucr.ac.cr \\ Recibido: 16 de febrero de 2021 / Aprobado: 17 de febrero de 2021 / Publicado: 12 de abril de 2021
}

\section{Resumen}

El pensamiento de Séneca sigue vigente y permite explorar áreas temáticas que han sido relegadas; por ejemplo, lo relacionado con aspectos políticos. Se presenta aquí un análisis teórico-bibliográfico sobre las implicaciones sociopolíticas de la forma en que cada uno lleva su vida y también sobre la necesidad de, por un lado, apropiarse de la muerte, como parte innegable de la vida misma, y, por otro, valorarla como opción cuando la persona ya no es útil a la comunidad humana. Considerando que, para el cordobés, si se desea una buena muerte es necesario haber tenido una buena vida, y, además, pese a la obviedad, que la vida y la muerte son el fundamento de la bioética y que ambas deben maximizarse y ser de calidad, se examinan acá las razones sociopolíticas por las cuales, desde la óptica del filósofo, es válido quitarse la vida. Con el fin de lograr lo anterior, se desarrollan los siguientes apartados: I. Simientes de la bioética: el buen vivir y el buen morir. II. Razones socio-políticas para morir. III. Consideraciones finales.

Palabras clave: Bioética, buen morir, buen vivir, calidad, muerte, quitarse la vida, Séneca, utilidad política, vida

\begin{abstract}
Seneca's thinking is still valid and allows us to explore thematic areas that have been, somehow, relegated; for example, political topics. This article presents a theoretical analysis on the socio-political implications of the way each one: a) leads his life and assumes death as an undeniable part of life itself and, b) values death as an option when the person is no longer useful to the human community. Considering that for Seneca, if a person desires a good death it needs to be preceded by good life, and also, despite the obvious, considering that life and death are the bases of bioethics and both must be maximized and be of good quality, the sociopolitical reasons why, from the philosopher's point of view, it is valid to
\end{abstract}


take one's own life are examined here. In order to achieve the above, the following sections are developed: I. Bases of bioethics: good living and good dying. II. Sociopolitical reasons for dying. III. Final conclusions.

Key words: Bioethics, Good Dying, Good Living, Quality, Death, to take life away, Seneca, Political contribution, Life

\section{Simientes de bioética: el buen vivir y el buen morir}

En los escritos de Séneca, la presencia del concepto buen vivir y su supuesta contraparte buen morir, permiten afirmar que en su doctrina filosófica se encuentran simientes de bioética, aplicables, tanto para la vida como para la muerte. En los escritos del filósofo se encuentran algunos requisitos que permiten colocarlo en el área de estudio de lo que actualmente es llamado bioética y tanatoética. Desde la visión de Bonete (2002, 60-68), en su artículo Ética de la muerte: de la bioética a la tanato-ética, sería así porque en las obras del filósofo está siempre presente la temática de la muerte desde una óptica histórico-filosófica-cultural y se educa sobre ella desde una mirada ética con el fin de incentivar su análisis, su aceptación, promover que se asuma con entereza y madurez, y también, para entender los impactos que deja en la vida de las personas. Asimismo, es innegable que en las obras de Séneca están presentes consideraciones psicológicas sobre la muerte y la vida. Esto es así porque mucho de lo escrito por el filósofo puede entenderse como una antesala para dejar la vida. Él hace que sus corresponsales se pregunten cómo vive cada uno su propio morir, lo cual se enlaza con el carácter biográfico de la vida y de la muerte, al igual que con los ritos que circundan el fenómeno de morir.

Lo anterior se agrupa, en gran medida, en los conceptos de buen vivir y buen morir. El filósofo hace un llamado a maximizar el buen uso de la vida, lo que en consecuencia devendría en una buena muerte. (Epístola 26, 8-10). Vida y muerte están entrelazadas, son caras de la misma moneda. La vida es un recurso que debe invertirse con sensatez, con prudencia, en todo aquello que la conforma. Lo importante de la vida no es por cuánto tiempo se prolongue, sino su calidad. Bien se lo explica a Lucilio: 
La duración de la vida se cuenta entre las cosas externas. Cuánto tiempo viva no depende de mí, pero que viva plenamente todo el tiempo de mi existencia depende de mí. Lo que se me puede exigir es que no pase una vida oscura, como entre tinieblas, sino que conduzca mi vida, que no sea arrastrado sin rumbo. (Epistola 93, 7)

No se trata, entonces, del número de años vividos sino su calidad. Además, la vida no se reduce al hecho de respirar día a día, a no estar muerto. Lo que se realice tendrá que hacerse de la mejor manera y trae consigo consecuencias tanto para quien actúa como para quienes reciben la acción, ya sea de manera directa o indirecta. En ello yace la calidad, la responsabilidad y la economía de existencia. El ser humano debería de ser como un mercader, valorar lo que va a ganar o perder, y nunca olvidar que lo gratuito se paga, en realidad a mayor coste (Epístola 42, 8). Si toma en cuenta lo anterior, potenciará un mejor y más adecuado uso de la vida, al igual que de los recursos que ella misma otorga.

En relación con lo anterior, es acertado preguntarse dos asuntos, por un lado, ¿cómo trabajar la bioética de la muerte cuando bios refiere a la vida misma?, y, por otro, ¿cómo explicar la posibilidad de una buena muerte? Para responder lo primero, que refiere al vínculo de la muerte con la vida, es útil pensar la vida como una cuerda. Toda cuerda cuenta con un inicio y con un final y puede reventarse en cualquier sitio y momento. La sección susceptible de romperse no puede negarse como parte de la cuerda, pese a su presencia y debilidad. En esa porción de la cuerda de la vida está la muerte como innegable. La muerte es parte integral de la cuerda de la vida aun cuando implique su destrucción, su acabamiento. En realidad, no importa qué sección de la cuerda sea la que se va a romper y tampoco es relevante en qué momento suceda; lo medular es tener presente la posibilidad de ruptura.

Sobre el segundo cuestionamiento, la buena muerte dependerá de una buena vida, del uso adecuado de la cuerda, su cuidado y fortalecimiento, que indefectiblemente estará mediado por condiciones o situaciones externas o internas a la persona. La vida estará siempre bajo la sombra y acecho de los dardos de la fortuna, que más que debilitar, deberían de ayudar a moldear la entereza, el carácter, la manera en que se enfrenta la adversidad (Epistola $65,24)$. 
El buen vivir está relacionado con la valoración que se tiene de la vida y con la manera en que se enfrentan las vicisitudes diarias. Cabe destacar que en las obras de Séneca son variados los usos de este concepto. Por ejemplo, a) se indica que el bien no consiste en vivir, sino en vivir bien; y que de la misma manera en que se vive bien, se puede haber vivido mal (Los Beneficios 3, 31). En Epístolas, b) se relaciona el buen vivir con los agravantes o atenuantes que afectan la posibilidad de vivir bien y se enfatiza en que, si alguna circunstancia impide vivir bien, ninguna impedirá morir con dignidad. (Epístola 17, 6.1). c) Se está en desacuerdo con aquellas personas que se lanzan al oleaje y que valoran como buena vida la que es agitada. Yerran quienes están inmersos en este tipo de vida, la aceptan e incluso pueden llegar a disfrutarla. El error es claro: el tener una vida cargada de múltiples objetivos, generalmente sin cumplir, evidencia un ánimo que no se asienta, que no encuentra puerto donde anclar (Epístola 28, 7.1). d) La vida, su acercamiento al buen vivir, se considera como un arte que requiere de la pericia suficiente para disparar en un blanco determinado, de manera que quien se ha preparado para la totalidad de la vida, no necesita consejos particulares porque está instruido para todo, sabe cómo vivir bien (Epístola 94, 3, 7), y para lograrlo, e) se vale de la honestidad y de la rectitud. Vivir con honestidad es incluso superior a la vida misma (Epístola 90.1.4), y apegarse a la rectitud es un bien que ayuda al buen vivir por lo que "[...] el sabio no vivirá lo que pueda, sino lo que deba" (Epístola 70, 4-6).

Un elemento indispensable para la vida recta es la tranquilidad del ánimo, condición que, como Séneca se lo explica a Lucilio y a Sereno, se reduce a un estado apacible de la persona sin engreírse ni deprimirse en razón de lo que le acontece. (Epístola 75, 18 y De la tranquilidad del ánimo, 2, 1). Lo anterior es posible solo si cada uno logra hacer examen de sí mismo, de las tareas que va a hacer y a causa de quién y con quiénes invertirá su tiempo y trabajo. (De la tranquilidad del ánimo, 6, 1).

En la cuerda de la vida, entonces, se enfrentan de manera continua, extensión y deber. La contienda es la vida misma, la cual, idealmente, se regirá por la rectitud. Habrá la posibilidad de vivir muchos años y que se vivan de manera recta, pero hay garantía. La cantidad de años no implica nada, lo importante es cómo se vive el período que a cada uno le ha correspondido (Epístola 85, 22). Esto es, la forma en que se enfrentan los dardos 
de la fortuna, que sin miramiento alguno a todos toca, a todos hiere, pero no a todos vence (Epístola 45, 9).

La vida ha sido otorgada como un don, hay que determinar qué hacer con ella y de qué manera aprovecharla. Pero la vida, que es un camino hacia la sabiduría, no es fácil. Su ruta puede ser escarpada y resbaladiza, estar atravesada por múltiples obstáculos e imprevistos. Ante esto, y pese a ello, Séneca enfatiza que el ser humano no está desamparado, cuenta con algunos medios para dirigir su vida de manera correcta. El recurso por excelencia es la naturaleza, que por el hecho de guardar equilibrio en sí misma, es ejemplo de buen vivir.

Séneca recuerda que aun cuando en la vida se mantenga la sensación de carencia, la naturaleza está provista por sí misma (Epístola 61, 4). Ella suministra todo, se basta a sí misma y abastece a todos de lo que se requiere. Lo que inserta el efecto de escasez en la cotidianidad es la ilusión y permanencia humana en falsas necesidades. La mayoría de las personas creen necesitar más de lo que ya tienen y, además, valoran como necesidad objetos materiales y condiciones de vida que no son, en realidad, necesidades si no, excesos o elementos superfluos ${ }^{1}$.

Los seres humanos olvidan continuamente apegarse a la naturaleza. Pasan por alto que el río da el agua, la caverna brinda la protección ante los estragos del clima, del árbol se cosecha la fruta y de la tierra el cultivo; básicamente, la naturaleza configura todo cuanto ella debe producir (Epistola $58,19)$. Pero el ser humano quiere más, es eso lo que es objeto de reproche. Así, por ejemplo, ante la sed y el hambre se excede por la gula (Epístola 124, 3) y si necesita protección, se alberga en un palacio con múltiples aposentos, aun cuando bastaría con una sola habitación (Epístola 90, 21), de una casa sencilla.

La comprensión errada de lo que es una necesidad y el exceso en su satisfacción hacen que la persona no alcance y no mantenga el equilibrio anímico, con lo cual también pierde la meta del buen vivir, de maximizar

1 Para Séneca, todo lo que sea gratuito debe observarse y valorarse con sospecha, debido que al final generará más gastos a quien lo recibe (Epístola 42,8). Asimismo, lo superfluo hace sudar (Epístola 4,10-11), pues "Todo cuanto parece que sobresale en la actividad humana, aunque sea insignificante y destaque por contraste con lo más bajo, no se alcanza sino a través de conductos difíciles y arduos. Escabroso es el camino hacia la cumbre de la dignidad [...] (Epístola 85,13). Estas afirmaciones están directamente relacionadas con la apreciación de la naturaleza como equilibrada y sabia, pues tiene, mantiene y ofrece lo necesario a todo aquel que de ella se valga (Epístola 25,4). 
la existencia, que es, en última instancia, la tarea a la que está llamado a cumplir quien pretenda lograr el buen vivir.

Lo anterior justifica, entonces, la primera simiente de la bioética: el buen vivir, e invita a cada uno a un proceso de reflexión continua sobre el qué, el cómo y el para qué de su vida, al igual que a asumirse desde la autosuficiencia, desde la negación del exceso, lo cual es útil por sí mismo y es válido considerarlo como requisito de la autonomía.

Ahora bien, si se trata de la contraparte del buen vivir, una segunda simiente de la bioética, pese a la obviedad, es la muerte misma, que para Séneca debería de ser buen morir. Vida y muerte son sombra de cada una respectivamente. Sirva para esta explicación del buen morir, la comparación de la vida con un barco:

Como en un navío que hace agua se puede obstruir una que otra grieta, mas, cuando ha comenzado a rajarse en muchísimos puntos y a ceder, no es posible socorrer la maltrecha embarcación, así en un cuerpo senil durante algún tiempo se puede contener y reparar la debilidad; pero cuando, igual que en un edificio carcomido, todo el ensamblaje se rompe y, mientras una pieza se ajusta, la otra se disloca, no queda sino estudiar el modo de evadirse. (Epistola 30, 2)

Así, si la vida es un barco al que se le da continuo, pronto y buen mantenimiento, su desgaste será proporcional al uso y cuidado, pero si se le abandona, en cualquier momento podrán colapsar sus estructuras y perder su funcionamiento. El barco es la morada, es la vida misma y como cada uno es responsable de su propia vida, se requiere estar al tanto de sus altibajos, lo que incluye la inminencia de la fortuna, pero particularmente, la de la muerte.

La muerte es de todos y para todos (Epistola 91, 16). Con el nacimiento se otorga la vida, pero a los humanos no solo eso se les entrega al nacer, ya que al lado de la vida se ofrece multiplicidad de opciones para morir. Es decir, por razón del nacimiento, la naturaleza abre la puerta a la vida y en ese mismo momento, la de la muerte. A partir de las etapas de niñez, adolescencia, período adulto y vejez (Epístola 49,3) se concreta la vida, pero estos períodos pueden ser rotos por los azares o caprichos de la fortuna (Epístola 65, 24) o, por qué no, por la voluntad propia, al provocarse su muerte (Epístola $70,5)$ o solicitar a otros que le ayuden a morir, como desesperadamente lo 
pide Hércules, luego de haber matado a su familia, por ser presa de la ira y la pérdida de la razón (Hércules loco, 1260-1270).

Se hacen evidentes dos situaciones, primero, el hecho de que cada persona es el único timonel de su propio navío y su tarea es cuidarlo. Segundo, que cuando sea necesario o incluso conveniente, se puede morir y valorar la muerte como opción, como vía de libertad. La responsabilidad de la propia vida, al igual que de la propia muerte, no tiene por qué ser delegada a otros. Cada uno: "[...] como experto navega con la vela rasgada y si pierde arboladura reajusta el resto del navío para la travesía" (Epístola 30, 3). Esta situación no se podrá evadir, cada uno es responsable tanto de lo que se hace como de lo que no. Está en sus manos moldear su vida y su muerte, siendo esta última, la mayor forma de libertad humana (Sobre la providencia 6, 8).

Tanto la vida como la muerte pueden ser caminos a la libertad, todo dependerá de cómo se lleven, de si se convierten en buen vivir y, por ende, en buen morir. De nuevo, vida y muerte son parte de un mismo proceso. De la calidad que se dé a la vida, dependerá, en mucho, la calidad de la muerte que se tenga. Para morir, lo único que falta es desearlo, ya que en la misma vida se encuentran los recursos para la muerte. Así lo explica Séneca a Novato:

Por su propia culpa se siente enfermo y de espíritu desdichado uno a quien le es posible dar fin a sus desdichas junto con él mismo. Se lo diré a aquel que fue a dar con un rey que apuntaba con sus flechas al pecho de sus amigos y a aquél cuyo señor atiborra a los padres con las entrañas de sus hijos: “¿Por qué gimes loco? ¿Por qué esperas o bien que un enemigo te vengue por medio del exterminio de tu pueblo o que un poderoso rey acuda volando a un país lejano? A donde quiera que mires, allí está el final de tus desgracias. ¿Ves aquel lugar escarpado? Por allí se baja a la libertad. ¿Ves aquel mar, aquel río, aquel pozo? La libertad está allí en lo hondo. ¿Ves aquel árbol escuálido, reseco, estéril? De él cuelga la libertad. ¿Ves tu cuello, tu garganta, tu corazón? Son medios para escapar de la esclavitud. ¿Te muestro salidas demasiado penosas para tí y que exigen mucho ánimo y entereza? ¿Quieres saber cuál es el camino a la libertad? Cualquier vena de tu cuerpo". (Sobre la ira, III, 15, 4)

La cita anterior enlaza con el campo de la bioética, particularmente por hacer referencia a la toma de decisiones y la dignidad, términos que desde 
la perspectiva Hottois (2011), en su artículo: ¿Qué papel tiene el principio de la dignidad en la toma de decisiones?, son vagos y ambiguos. Vagos por falta de claridad o exactitud y ambiguos, debido a que siempre se podrán entender o interpretar de diversas maneras; según sea el uso que se les dé y las perspectivas en las cuales se engloben. Aun así, sobre la expresión morir con dignidad, el autor explica que:

[...] permite, no obstante, una triple referencia a la calidad de vida, a la autonomía y a la dignidad. El individuo debe ser libre (es la autonomía) de evaluar que en ciertas circunstancias (es la calidad de vida), según propia estimación (estima de sí) y según la de los demás (tal como percibe las miradas ajenas) la vida no puede ser vivida con suficiente dignidad. Su última dignidad desde entonces consiste en escoger quitarse la vida considerada insoportable. Aquellos que no reconocen esta libertad y esta dignidad, confunden en realidad dignidad con sacralidad de la vida. (p. 22)

En la tarea de lograr un buen vivir para llegar, idealmente, a un buen morir, influyen calidad de vida, autonomía, dignidad, autoestima, hetero-estima, que es la estima que se recibe de parte de los otros, conceptos que se encuentran en el pensamiento senequiano, aunque, como es esperarse, bajo otra terminología. La calidad de vida refiere, además de lo ya señalado bajo el concepto de buen vivir, a la necesidad de promover y mantener equilibrio en la vida, en su sentido biológico. De igual manera, a la concordancia entre las acciones, los pensamientos y las pasiones. No tendrá calidad de vida aquel que se entregue a excesos, y tampoco quien no refleje con sus acciones sus palabras o no controle sus pasiones ${ }^{2}$.

Sobre autonomía y dignidad es necesario desarrollar, por lo menos un poco, estos conceptos. Para el cordobés, la autonomía yace en el ejercicio racional y libre de la toma de decisiones y en la evaluación de sí y de las circunstancias. Este examen es recomendado, no es obligado, ni estará ligado a coerción alguna. Será siempre una ganancia por el hecho de potenciar

2 Séneca sabe que el camino del buen vivir es complicado. Tiene claro que si bien el ser humano es racional y se vale de esta capacidad para intentar controlar sus pasiones, estas, además de ser muy poderosas porque llevan, en la mayoría de los casos, al placer, realmente le pueden desviar del buen vivir; por el hecho de que no es posible renunciar a la existencia de las pasiones, apostar por regularlas será la manera de acercarse a una vida equilibrada y, como consecuencia de ello, a un buen morir. Quien desee ser sabio debe enfrentarse a muchas formas e intensidad de pasiones, y recordar que: "Jamás los vicios se amansan noblemente" (Epistola $85,8)$. 
y ayudar a mantener la tranquilidad anímica. El llamado al escrutinio de sí mismo y de las circunstancias que acontecen, es un acto de libertad porque depende de la voluntad de cada uno. No es, ni será nunca, un mandato. Séneca exhorta, pero no obliga, por lo que estará en cada uno el llevarlo a cabo o no, y cuando se haga, disfrutar de sus beneficios, ya que:

¿Qué, pues, más hermoso que esta costumbre de revisar toda la jomada? ¿Qué sueño el que viene después del examen de uno mismo, qué tranquilo, qué profundo y despreocupado, cuando el espíritu se ha visto alabado o aleccionado y ha instruido proceso, inquisidor de sí mismo y censor secreto, a su conducta! (Sobre la Ira, III, 36, 2)

La dignidad, para Séneca, es de carácter ontológico. Se es digno por el solo hecho de ser humano, por lo que las limitaciones a ella estarían dadas por factores externos a la persona, que generalmente están estipulados por convenciones sociales. Desde el punto de vista del filósofo no se requiere de nada extraordinario para valorar a otro como digno; las dificultades radican en lo que, por un defecto de tasación, la sociedad utiliza como variable para valorar a alguien como más o menos digno.

Las cualidades o condiciones externas a la persona, como la clase social, el dinero, las riquezas materiales, el lugar y clasificación de nacimiento, por ejemplo, nacer libre o esclavo, no afectan, no deberían de afectar, en mayor o menor grado, que alguno sea considerado como lo que es: persona, y por ello, digno. Es así porque se omite que todos los seres humanos son esclavos, aun gozando de la clasificación sociopolítica de "libre", ya que la fortuna afecta de igual manera a los esclavos que a los libres (Epístola 47, 1). Al ser esto así, definitivamente se ponen en tela de juicio dos asuntos. Primero, las clasificaciones y las consecuentes jerarquías sociopolíticas que de ellas se siguen; segundo, la base ontológica de la dignidad humana.

Desde la actualidad, así lo explica y problematiza Pelé (2004):

[...] Con el concepto moderno de dignidad el valor del individuo yace únicamente en sus rasgos humanos independientemente de su posición social, origen o filiación. La excelencia del hombre es de cada uno no por su pertenencia a una élite sino a la especie humana. [...] Los fundamentos modernos de la dignidad pretenden justificar la dignidad humana únicamente en los 
rasgos humanos con el fin de justificar la idea de igual dignidad. Igual dignidad que es el fundamento del Estado de Derecho que considera a los individuos como ciudadanos con iguales derechos y deberes. Sin embargo, dichas fundamentaciones tienen poca relevancia práctica: en efecto, por un lado, dan por sentado y obvio que por su excelente naturaleza, el ser humano tiene un valor absoluto y es merecedor de derechos; por otra parte, dicha obviedad choca con las numerosas situaciones actuales y pasadas donde individuos han visto degradado y vulnerado su dignidad. Con otras palabras, si el valor del ser humano es tan obvio - por derivar precisamente de los rasgos que caracterizan a los seres humanos - ¿por qué no se impone en la realidad con tanta obviedad? (p. 11)

La respuesta que da Séneca al problema planteado por este autor, está en lo que se ha explicado anteriormente, en el peso y contrapeso errado que la sociedad de la época del filósofo y todavía la actual, otorgan a variables que son en sí mismas indiferentes, es decir que no son ni buenas ni malas (Epístola 117, 9 y Epístola 82, 10).

Lo anterior podría entenderse como una contradicción, sin embargo, no lo es. Lo que se presenta es, eso sí, una distancia entre el ideal doctrinal planteado por el filósofo y la realidad que se vive en la cotidianidad, que, como se señaló en líneas precedentes, está permeada por falsas necesidades que llevan a que los seres humanos valoren, de forma errada, a sus pares y a su propia vida. La equivocación recae, de nuevo, en la tasación ya que las variables a las que comúnmente se les da peso para delimitar quién es no digno, en realidad son indiferentes. Es decir, no suman ni restan nada a la persona como tal.

De lo anterior se sigue que por el hecho de que la vida es un don que cada uno debe decidir cómo utilizarlo, habrá momentos en los que, por diversas razones, será apropiado dejar de estar en el mundo, será apropiado acabar con la propia vida. Por ejemplo, cuando todo aquello que era posible hacer en favor de sí o de otros, ya se ha hecho o ha sido imposible hacerlo. Cada uno puede ejercer su autonomía y libertad para cortar el vínculo con lazos fraternos inmediatos, como la familia y los amigos; y con los lazos fraternos mediatos, como la sociedad misma. Pero, aun con la autonomía y la libertad, e incluso con la aceptación de que se puede decidir morir por amor 
propio, por autoestima, no es debido pasar por alto el aprecio que otros tienen hacia la persona que ya no quiere, no puede o no debe morir, ni la forma y grado de afectación que las decisiones propias tienen sobre otros. Es decir, aun cuando acabar con la vida propia es un asunto de orden privado, estrictamente personal, alrededor de esta decisión está la heteroestima, el vínculo afectivo que los otros tienen respecto al que va a morir. Y, también habrá de estar presente el peso social y político del acto de acabar con la vida propia.

\section{Razones socio-políticas para morir}

Debe reiterarse, entonces, que calidad de vida [y de muerte], autonomía, dignidad, autoestima y hetero-estima, son aspectos que permiten no solo comprender el deseo y el acto de terminar con la vida propia, sino también discutir la temática, pues el buen vivir y el buen morir, no son fenómenos aislados, se dan en la comunidad humana, que es, sociopolítica.

Los escritos de Séneca no presentan un ideal de ser humano y de comunidad sociopolítica que sea totalmente ajena a la cotidianidad y a la manera como ella se construye y mantiene. Se trata, más bien, de un perfil humano y comunitario en el que subyace la idea de que lo importante es el equilibrio y tranquilidad anímica de sus integrantes, al igual que el intercambio justo de bienes y servicios en la comunidad, que es en sí mismo un beneficio y la razón por la cual seres humanos se congregan en común unión. Para lograr el balance anímico y el intercambio justo es necesario el apego a la mesura y desechar de sí todo exceso, también se requiere que cada uno, valiéndose de la racionalidad, examine continuamente las circunstancias de su vida y la manera en que se enfrenta a ellas. ¿Por qué? Porque lo deseable es no seguir cometiendo errores de tasación y no ser presa de la desdicha.

Séneca invita a que las personas se detengan, estén atentas y revisen tanto sus acciones como lo que les circunda. Cada uno, al estar supeditado a múltiples determinaciones externas e internas, tendrá que hacer un alto en el camino con el fin de observar qué está a su alcance cambiar o no, en qué sentido podrá cambiarlo y para qué potenciar ese cambio. Esto es así porque la propuesta senequiana funciona, de manera tácita, como una promesa de economía existencial. En otras palabras, dada la dificultad de vivir la vida, el poder filtrar continuamente las acciones diarias, la determinación de qué hacer, que no y cómo hacerlo, es una de las estrategias que quien desee un 
buen vivir, debe ejercitar. La filtración no es exclusiva de la vida; se aplica, de igual manera, a la muerte, al tipo de muerte que se desee tener.

El derecho sobre la propia muerte no puede ni debe depender del criterio de otros, es cuestión exclusiva de cada uno. Dar cuentas de la muerte no es asunto público, es una tarea que concierne única y exclusivamente al que está en proceso de muerte o al que la anhela. Por ello, Edipo, presa de la desesperación, ansioso de acabar con su propia vida, le dice a su hija Antígona:

[...] Es un crimen impedir que muera uno que lo desea. Ni siquiera es igual, lo segundo es más grave, creo yo: prefiero que se me imponga la muerte a que se me arranque de las manos. Deja tu propósito muchacha; el derecho sobre mi vida y sobre mi muerte me pertenece a mí. Yo he abandonado mis reinos voluntariamente, pero retengo el reinado sobre mí mismo. Si eres una leal compañera, entrega una espada a tu padre, pero la célebre espada con que él mató a su padre. (Las Fenicias 93-107)

Pero se presenta una dificultad básica, que es la que abre el portillo al análisis sociopolítico de quitarse la vida, y es que aun cuando la decisión solo compete a quien busca morir, está en proceso de muerte o la desea, la persona tiene vínculos sociales, políticos y afectivos que no le exoneran de la mirada, del escrutinio de la sociedad por vía del cumplimiento de normas y, como se indicó en párrafos precedentes, según Hottois (2011), de la heteroestima.

Si bien Séneca siempre dará mayor peso a lo que decida cada uno, eso no elimina la afectación, directa o indirecta, a otros. Para matizar el derecho a terminar con la propia vida, se sirve de razones, de orden sociopolítico y afectivo, tales como la utilidad, que da sentido al quehacer de la vida (Epístola 60, 4), luchar por la familia, por el padre (Epístola 88, 7) y la esposa (Epístola 94, 3), por ejemplo; los amigos (Epístola 9, 10) y la patria (Sobre la ira, III, 28, 5).

Por el hecho de que poder escoger terminar o no con la propia vida es un acto de autonomía y libertad, es también una forma de dignificación. Sin importar si la vida que se tiene es tolerable o no, optar por no vivir será siempre una posibilidad. Asimismo, hay que recordar que habrá quienes, ante el primer agravio de la fortuna, querrán morir y quienes, habiéndose apegado al buen vivir, se apartan de la vida por haber logrado hacer de ella la mejor posible o porque, en razón de su dignidad, deciden no ser objeto 
de ninguna forma de sumisión o humillación, como es el caso de un esclavo que Séneca menciona, quien:

[...] destinado al espectáculo matinal, bamboleándose como dominado por el sueño, dejó caer la cabeza hasta introducirla entre los radios de la rueda, y se mantuvo en su asiento hasta tanto que el giro de ésta le cortase el cuello: en el mismo vehículo que le conducía al suplicio, escapó de éste. (Epístola 70, 23)

Al igual que el esclavo, apegados al buen vivir, se encuentran Sócrates, Catón, Lelio y Druso Libón. El cordobés, le recomienda a Lucilio, su pupilo y amigo, que imite a Catón (Epístola 11,10) y también le explica que el poder terminar con la vida es una forma de libertad que ennobleció a Sócrates con la cicuta y a Catón con la espada (Epistola 13, 14).

Si se toma como referencia lo anterior, la muerte de Sócrates y Catón e incluso del mismo Séneca cobra matices políticos. Sócrates es acusado de impiedad (Epístola 104, 28), Catón se niega a someterse al domino del César (Epístola 104, 29) y Séneca debe cumplir la voluntad, probablemente caprichosa, de su pupilo, el emperador Nerón, luego de una vida personal y política plagada de intrigas, desavenencias y sinsabores (Tácito, Anales, XIV 53-54).

Las condiciones que impulsan el deseo y consumación de la muerte de ellos tres son particulares, debido a que no parecen estar expresamente relacionadas con algún grado o forma de hastío hacia la vida como tal. Aunado a esto, los tres personajes están anuentes a cumplir con el deber de morir. Así, por ejemplo, Séneca explica que Sócrates, al aceptar la muerte y la cárcel, prefirió el deber aun cuando tenía garantizado quiénes le ayudaran a fugarse del presidio (Epistola 24, 4). Finalmente, es particular también el hecho de que las condenas a quitarse la vida eran una sentencia política, mediada por alguna forma de supuesta compasión, idea que estaba relacionada con el grado de exposición de la muerte, ya que, como explica Garrido (2000, 5152), en su artículo La pena de muerte en Roma antigua. Algunas reflexiones sobre el martirio de Emeterio y Celedonio, albergando la idea implícita de restauración del orden y de aleccionamiento moral, la mayoría de condenas a muerte se ejecutaban en público, mientras que el acto de acabar con la vida propia, se daba en privado. 
La vida es de cada uno, la muerte lo es también. Si se reconoce que, para Séneca, uno de los aspectos que dan valor a la vida es el lazo sociopolítico, al igual que la manera en que se es útil a la comunidad humana porque "[...] en comunidad de la naturaleza, ella se bastaba como madre para proteger a todos [...]" (Epístola 90, 38). Entonces, cuando desde la perspectiva de quien desea morir, ya no hay nada que aportar, básicamente cualquier congénere, la familia, los amigos, y la patria, se convierten en razones válidas para dejar de vivir. Es aquí donde calza la utilidad, como motor ético y político, ya que:

[...] lo que se exige del hombre es que sirva a los hombres, si puede ser, a muchos, si no, a unos pocos, si no, a los más cercanos, si no, a sí mismo. En efecto, cuando se hace útil a los demás, se ocupa de un asunto público. Tal como quien se hace peor no se perjudica tan sólo a sí mismo, sino también a todos los que, si hubiera hecho mejor, habría podido servir, igualmente todo el que se perfecciona a sí mismo precisamente por eso sirve a otros, porque les prepara a uno que les va a servir. (Del ocio, 3,5$)$

Así, una de las razones de la vida, es, entonces, ser útil y la utilidad puede enmarcarse en el ámbito social y político. Aun con lo controversial que es la posición senequiana sobre el inmiscuirse o no en asuntos políticos y públicos ${ }^{3}$, una de las formas de maximizar la vida, de ser útil a sí mismo y a los demás, es precisamente dedicarse a ellos. Al ser esto así, si no se cumple adecuadamente con estas dos tareas, habrá razones suficientes para no permanecer con vida. Sin embargo, para poder fundamentar lo que se

3 El filósofo mantiene posiciones vacilantes sobre la participación en asuntos políticos y públicos, las cuales cambian según sea el texto que se analice, y, por ende, el tema que se trate. Asimismo, es acertado afirmar que uno de los factores que hace que cambie de opinión sobre este tema es el sin número de dificultades que tuvo que enfrentar y tratar de resolver cuando cumplió con estos cargos. ¿Se debe dedicar una persona a los asuntos políticos y públicos? Depende de cada situación. Por ejemplo, en De la tranquilidad del ánimo, 4, 2, Séneca le recomienda a Sereno que se mantenga en su cargo político ya que la labor de un buen ciudadano nunca será inútil; mientras que en Sobre la brevedad de la vida, 18, 3, le asevera a Paulino que: “[...] es mejor sacar las cuentas de la vida de uno que las del trigo público"; exhortándolo con esta afirmación, a que revise las tareas que merecen ser realizadas. Por otra parte, en Epístolas, no siempre invita a Lucilio para que siga en sus puestos y labores. En la Epístola 19, 5-9, le indica que lo mejor es no ocuparse de cargos públicos, y en la Epístola 22, 1, le pide que preste atención, pues los asuntos políticos parecen brillar cuando en realidad son opacos. Para finalizar, recuérdese que Séneca fungió como abogado y en la Epístola 8, 6 critica su propia función pública e invita a no hacer nada. Entonces, aun cuando apela a la bondad del ser humano, como recurso ideal para el ejercicio de asuntos políticos (Sobre la clemencia I, 1, 4) y exhorta y refuerza el principio estoico de conservación de la humanidad, a partir de la evitación de lo nocivo (Epístola 121, 21), ve en las tareas políticas, uno de los trabajos más desgastantes, que potencia con mayor facilidad el desequilibrio anímico, promueve la corrupción y lleva, en síntesis, a la infelicidad. 
acaba de afirmar, se requiere un breve camino argumentativo que permita establecer la ligazón entre la vida útil en el campo sociopolítico y aspectos bioéticos. El mismo Séneca ofrece las pautas.

La utilidad, entendida como maximización de recursos y de intercambio justo de dones entre congéneres, es la simiente de la sociedad, fomenta buena convivencia humana, ayuda a gestar y mantener relaciones sociopolíticas menos desequilibradas (Los beneficios I, IV y XIV). El individuo es corpóreo, su cuerpo lo ubica en el mundo como ser humano, no así, como planta o animal. Por sí mismo, el cuerpo le es útil, de hecho, es la razón primera de su permanencia en el mundo y, como consecuencia, ese cuerpo material, biológico, debe ser cuidado y maximizado según sea la etapa de su desarrollo. Es de esta manera porque a cada período de la vida corresponde una tarea, se navega por la vida cumpliendo cada etapa, hasta vislumbrar el propio acabamiento o el de la humanidad (Epistola 70, 2) y, sin un cuerpo sano, las posibilidades de ser útil a sí mismo y a los demás decaen o se anulan.

El ser humano es corporeidad, pero no se reduce a ella. Cada uno trasciende su cuerpo por el hecho de ser social, cualidad que se da porque: "[...] existe la aversión a la soledad y [...] [a] como la naturaleza une a los hombres entre sí, así también para este sentimiento existe un estímulo que nos hace deseosos de amistad" (Epístola 9, 17). La característica de ser social, tiene su fundamento teórico en varios asuntos. Primero, en la proclamación del amor a sí mismo y a los congéneres, amor que es compartido con los animales, a quienes: "El primer instrumento que la naturaleza les ha otorgado para su conservación es la adaptación y el amor a sí mismos" (Epístola 121, 24). Segundo, el sentido de comunidad, por el hecho de que los seres humanos han nacido para agruparse, para regirse por lo común en lugar de lo individual (Epístola 95, 53). Tercero, el cosmopolitismo, al establecer, tomando como base la idea de la gran República y la pequeña República, que se es ciudadano del mundo y que las fronteras son irrelevantes para efectos de la igualdad entre los seres humanos (Epistola 47, 10; Epístola 95, 50 y Los beneficios III, 28, 1-2).

Pero, si lo que se desea es establecer la relación analítica entre lo biológico y lo social, se requiere tener en cuenta que la sociedad es vista, por Séneca, como un organismo en el que si una de sus partes está enferma habrá repercusiones para las otras partes por separado y para la totalidad, de 
manera tal, que la relación y grado de salud o enfermedad (en lo físico, lo social y lo político) determinará no solo el quehacer político, sino también qué tanto y de qué forma se logra ser útil a sí mismo, a otros, a la comunidad en general y al ente gobernante, que en el momento histórico del cordobés, era el Imperio, liderado por el emperador.

Séneca le explica a Nerón esta correspondencia de lo corpóreo-biológico con lo corpóreo-sociopolítico. En Sobre la clemencia I, 4, 2, le instruye sobre el uso adecuado del poder, a partir de la analogía de la cabeza y el cuerpo, que guardan la misma relación de dependencia del gobernante con el pueblo, ya que el primero está supeditado al segundo para poder mantener su poder y ambos se aceptan en razón de las ventajas recíprocas que reciben. Los gobernados obtendrán variados beneficios al ceder su agencia al gobernante, y, por otra parte, el que gobierna, tendrá, además del poder que por sí mismo le da su cargo, la ventaja de ser valorado como superior y, por ende, como digno de obediencia.

Sumado a lo anterior, se acepta la relación de subordinación entre las partes porque, por lo menos en el plano ideal, al igual que sucede con la decisión de mantenerse con vida o no, el vínculo entre ellas no debe darse por la fuerza; más bien, debe basarse en la inteligencia, en la racionalidad. El gobernante, que ya es visto como superior y a quien se le ratifica esta superioridad con la obediencia, en lugar de usar la fuerza, desempeñará en la comunidad sociopolítica la función que la racionalidad cumple respecto al cuerpo en el ser humano. Es imperante que sea así por una razón de salud, de utilidad y conveniencia, pues:

La buena salud se extiende desde la cabeza a todas las partes del cuerpo: son vigorosas y firmes, o abatidas por la debilidad, según que el espíritu esté vivo o languideciente. Serán los ciudadanos dignos de esta bondad, lo serán los aliados, y las buenas costumbres volverán a todo el orbe. (Sobre la clemencia, II. 2.1)

Si hay buena salud hay buen vínculo y también lo habrá por vía de la utilidad. Ser útil se convierte, de esta manera, en un punto de inflexión en lo sociopolítico y en lo personal. La utilidad define la pertinencia, o no, de cortar los lazos con la vida o permanecer en ella, en particular si la persona trabaja en tareas políticas y públicas. 
Cuando se es útil, se puede permanecer en los asuntos políticos y públicos, pues ellos, para Séneca, son un servicio, una forma de vitalidad en las dinámicas relacionales a las que se pertenece. Quien se ocupa en estos asuntos tiene el deber de servirle a la comunidad humana (la gran República), al país al que pertenece (la pequeña República) y, cuando no lo pueda hacer, buscará ser útil, por lo menos a otro congénere o a sí mismo. Eso es lo esperable, sin embargo, puede ser que no se logre y por ello, al igual que sucede con el cuerpo cuando se deteriora, dejar de vivir se transforma en un deber sociopolítico, cuando, aun con todos los esfuerzos, impera la inutilidad.

El grado de utilidad o inutilidad sociopolítica, y, por ende, ética, se relaciona con la poca o nula injerencia en el mejoramiento de la vida propia o de otros. Si cada uno es dueño de su vida y de su muerte, y mantenerse en vida o no, es un ejercicio de autonomía y libertad que está mediado por factores personales; esta autonomía y libertad es aplicable, de igual manera, a lo sociopolítico, cuando lo que se cuestiona es la utilidad como vínculo y deber para consigo y los otros.

Existen, entonces, no solo razones personales que justifican que se decida terminar con la vida propia. También las hay de orden sociopolítico, como lo son: a) el ofrecer la vida para así obtener el favor de los dioses, que es el caso de Edipo, quien desea morir para poder expiar su culpa porque sin saberlo ha matado a su padre y ha contraído matrimonio con su madre; b) morir por deber patriótico, situación que vive Catón (Epístola 14, 13) y, c) la inutilidad, que es, básicamente, haber perdido la posibilidad de hacer favores, beneficios, a los otros (Sobre la vida feliz 24, 3).

Estas razones no surgen de la nada, son, claramente, producto del contexto sociohistórico romano y del tipo de vida que se opta por llevar. Asimismo, parece ser evidente que la forma de ser única e irrepetible de cada uno, su deseo y tendencia al equilibrio anímico, la capacidad o incapacidad de mantenerlo, al igual que la entereza o flaqueza ante la adversidad, influirán en la decisión de mantenerse o no en vida; sin importar si se trabaja en asuntos políticos y públicos, o no.

Pese a lo anterior, aquel que se entregue al reto del buen vivir para con ello potenciar un buen morir, buscará ser de utilidad a la humanidad, y cuando no pueda hacerlo, tendrá que retirarse, ya sea del cargo o incluso de la vida misma. La permanencia en vida está determinada, de esta manera, 
por el servicio que se pueda dar a otros o a sí mismo, por lo que vivir o no vivir se transforma en opción o deber.

\section{Consideraciones finales}

¿Bajo qué términos, entonces, en el pensamiento de Séneca, existen simientes bioéticas que enlazan con asuntos políticos y que hacen que estos puedan ser considerados desde una perspectiva bioética? Sirva la siguiente cita, para ilustrar y explicar:

Es abominable hacer daño a la patria; luego también a un ciudadano, pues él es parte de la patria (las partes son sagradas si el conjunto es digno de veneración); luego igualmente a un hombre, pues éste es conciudadano tuyo en una urbe más grande. ¿Qué, si las manos quisieran hacer daño a los pies, a las manos los ojos? Igual que todos los miembros están de acuerdo porque interesa a la totalidad conservar cada uno, así los hombres respetan a cada uno, porque han sido engendrados para la vida en común, pero la sociedad no puede estar segura si no es por medio de la preservación y la estima de sus componentes. (Sobre la ira, II, 31,7)

En primera instancia debe afirmarse que en toda la obra del pensador subyace la idea de entender la sociedad y las relaciones de quienes la conforman, como un organismo. La concordancia estructural biológica del cuerpo con las funciones que debe cumplir cada órgano, se traslada a la concordancia y equilibrio que demanda a la comunidad humana. Cada parte, por ejemplo, las manos, los ojos o los pies, como se indica en la cita, cumple lo que le es propio sin reñir con las funciones de las otras partes, lo que en lo sociopolítico se traduciría en que, si cada uno se dedica a servir y ser útil, según le corresponda, contribuye no solo a su equilibrio personal, sino también al de la sociedad. De no ser así, ambos, cuerpo y sociedad, se enferman porque los mecanismos correctos para su regulación han fallado parcialmente o son completamente disfuncionales, cayendo en desbalance.

Lo anterior remite a la relación parte-todo y a la triada ética-física-lógica, propia del estoicismo. Sobre la parte y el todo, valga señalar que el cuerpo, al igual que la comunidad sociopolítica, es un todo, donde la afectación de una parte, deja huella no solo en las otras partes sino también, en la totalidad misma. Esto es de alcance ético y político por el carácter "sumativo" de las 
relaciones humanas que pasan, indefectiblemente, de un yo a un nosotros, y que para el Séneca se sintetizan en la simpatía y sentido social humano, dado que las personas buscan relacionarse con otros, siendo esto la simiente de la sociedad y un beneficio.

Cada uno, se relaciona consigo mismo y con núcleos de personas que aumentan o disminuyen en cantidad y difieren en calidad. El vínculo del yo con la otredad, por ejemplo, puede ser yo-familia, yo-vecindad, yo-comunidad específica, yo-país, yo-mundo; lo cual, para el filósofo, está contenido en los conceptos de pequeña y gran República, al igual que en el concepto de cosmopolitismo.

Por otra parte, es necesario mencionar la concatenación y paralelismo entre la tríada ética-física-lógica y la del individuo-ente gobernante-sociedad. Las acciones individuales afectan a los demás, por ello, es necesario valerse de la racionalidad para determinar qué se hará, cómo, para qué y en quiénes se invierte esa acción. No podría valorarse como éticamente responsable una acción, ya sea individual o colectiva, que omita el examen de las consecuencias que de ella se siguen. De hecho, si la persona se detiene para revisar la razón y curso de lo que hace, se está comprometiendo consigo y con los otros; busca protegerse y proteger, lo cual, además de ser un asunto político, es útil, y contribuye a la economía de la existencia humana.

Otro aspecto bioético-político presente en la filosofía de Séneca es la invitación, el imperativo, hacia el buen vivir y consecuentemente, al buen morir, ligados, de nuevo, a la forma y grado de utilidad que puede darse para consigo mismo y hacia los demás. Esto enlaza con calidad de la vida y de la muerte, con la dignidad y con la toma de decisiones, que es lo que conforma la autonomía y abre la puerta a la libertad. Es así porque en la toma de decisiones se materializa el actuar de cada uno y si se es consistente con el mandato de concordancia del estoicismo, no se podrá servir y ser útil a los otros siendo inútil a uno mismo.

No se hace referencia únicamente a un cuerpo que poco a poco pierde sus funciones, se trata de qué tanto se puede hacer por sí mismo y por los otros, del beneficio que se tiene y que se ofrece a sí mismo y a los otros cuando las condiciones materiales, biológico-estructurales y anímicas de la persona ya no son suficientes para que su vínculo con la otredad sea de calidad y, por ende, no vaya en detrimento de nadie. 
De eso se trata la vida, de su maximización para lograr un buen vivir, $y$, consecuentemente, para la potenciación de un buen morir. Pero, para entender esto y llevarlo a la práctica, cada uno tendrá que aceptar que su estancia en la vida es pasajera, que en el tránsito del camino, en cada recoveco puede encontrarse con la muerte y que, debido a ello, es decir, a la inminencia de la muerte y la inmediatez de la vida, su responsabilidad será siempre hacer de la vida la mejor posible, durante el tiempo que pueda o quiera; lo cual en el campo sociopolítico se puede lograr por la responsabilidad, el servicio y la utilidad a los congéneres.

Tal es el peso de lo sociopolítico, nunca desligado de lo personal, que cuando se comete alguna falta, el ser humano busca ocultarse, mientras que en los momentos en los que no es así, se presenta airoso frente a los otros, sin problema alguno. Por ello, como lo asevera Séneca:

La buena conciencia apela al público; la mala, hasta en la soledad se encuentra angustiada y preocupada. Si son honestas tus acciones, todos deben saberlo; si son torpes, ¿qué importa que nadie lo sepa, puesto que tú lo sabes? ¡Desdichado de ti si desprecias ese testigo! (Epistola 43, 5)

Se es testigo de sí mismo, engañarse sobre lo útil o inútil que se está siendo, es un sinsentido. En la mayoría de los casos las personas tienen claridad de lo que hacen con su vida, se está al tanto de lo que aleja del buen vivir o de lo que le acerca a él y también, aunque con menos frecuencia, se tiene presente que la vida puede acabar en cualquier momento. La vida es una construcción, que, como cualquier asunto humano, es perecedera; se erige según las bases y preceptos que la persona decida mantener. En el proceso, si bien se puede errar, también es posible re-direccionar lo que se hace, aprender de los errores y rectificarlos; sin embargo, hacerlo o no, es una decisión personal.

A las decisiones se le une algo que queda libre de las influencias y determinaciones a las que se ve expuesto cada uno; ese algo es la voluntad. Voluntad para dirigirse al buen vivir, o no, para vivir una vida recta, o no; para ser responsable o no, y también para buscar la libertad.

Séneca, pudo haber huido de la cárcel, no lo hizo, Sócrates y Catón no se dejaron avasallar por las presiones políticas, y vieron en su propia muerte 
la manera de hacer patente su criterio sobre los cambios sociopolíticos y éticos que acontecían en el momento. Los tres decidieron morir con dignidad en lugar de suplicar por la vida. Optaron por dejar de vivir pues "No tiene derechos la fortuna sobre la conducta moral" (Epistola 36, 5) y siempre "[...] debemos preferir la muerte más inmunda a la más noble esclavitud" (Epístola 70, 21). La esclavitud puede ser el dedicarse a los asuntos políticos y públicos, que en la mayoría de los casos hacen sufrir (Epístola 74, 2). Si es así, que no se olvide que el camino a la libertad está en cualquier vena del cuerpo (Sobre la ira, III, 15, 4).

\section{Referencias}

Bonete, E. "Ética de la muerte: De la bioética a la tanato-ética". $\Delta \alpha i ́ \mu \omega v:$ Revista de Filosofia, 25, 57-74. (2002). Recuperado de: https://revistas.um.es/daimon/article/ view/14801/294961

Garrido, J. "La pena de muerte en Roma Antigua. Algunas reflexiones sobre el martirio de Emeterio y Celedonio. Kalakorikos, 5, 47-61 (2000). Recuperado de: https://dialnet. unirioja.es/servlet/articulo?codigo=192209

Hottois, G. “¿Qué papel tiene el principio de dignidad en la toma de decisiones?” En Boladeras, Margarita. (Ed.), Bioética, la toma de decisiones, 17-48. España: Editorial Proteus. (2011).

Pelé, A. "Una aproximación al concepto de dignidad humana". Universitas: Revista de filosofia, derecho y política, 1, 9-13 (2004). Recuperado de: http://universitas.idhbc. es/n01/01_03pele.pdf

Séneca. Diálogos: Consolaciones a Marcia, a su madre Helvia y a Polibio \& Apocolocintosis. Madrid: Gredos (2008).

Séneca. Epistolas morales a Lucilio I. Madrid: Gredos (1986).

Séneca. Epistolas morales a Lucilio II. Madrid: Gredos (1989).

Séneca. Sobre la clemencia. Madrid: Tecnos (1988).

Séneca. Tragedias I. Madrid: Gredos (1979).

Séneca. Tragedias II. Madrid: Gredos (1980).

Séneca. Tratado de los beneficios. Santiago de Chile: Ercilla (1941).

Séneca. Tratado de los beneficios. Madrid: Ediciones Ibéricas (1956).

Tácito. Anales del Imperio romano: Desde la muerte de Augusto a la de Nerón (Trad. C. Coloma). Barcelona: Iberia, 1986. 